\title{
Algunos problemas metodológicos y teóricos de la enseñanza de la sintaxis del español como asignatura universitaria (ELE)'
}

\author{
Some methodological and theoretical problems in teaching \\ Spanish syntax as an academic subject (SFL/ELE)
}

Petr Stehlík

Universidad Masaryk de Brno, República Checa

\begin{abstract}
Resumen: El artículo se ocupa de algunos problemas de carácter metodológico y/o teórico a los que se enfrentan los docentes de sintaxis como asignatura académica (obligatoria dentro del programa de Filología Hispánica en los países no hispanohablantes) y que resultan, en su mayoría, de la evidente falta de una concepción unificada de la sintaxis del español. Según intentamos mostrar, esta circunstancia se traduce en una considerable diversidad terminológica, definitoria y clasificatoria que presentan los manuales (y las gramáticas) publicados en España, lo cual, a su vez, dificulta la exposición de los fundamentos teóricos al igual que la selección de materiales didácticos apropiados.

Palabras clave: español LE, sintaxis, enseñanza, metodología, teoría.
\end{abstract}

Abstract: The article deals with some methodological and/or theoretical problems faced by teachers of syntax as an academic subject (compulsory within the Programme in Hispanic Philology in non-Hispanic countries) and resulting mainly from the obvious lack of a unified conception of Spanish syntax. As we try to demonstrate, this circumstance translates into a considerable diversity of terminology, definitions and classifications used in different manuals (and grammars) published in Spain, which in turn makes it more difficult to expound the theoretical basis of the discipline as well as to select appropriate didactic materials.

Keywords: Spanish FL, syntax, teaching, methodology, theory.

\section{Introducción}

La mayoría de los lingüistas y especialistas en didáctica interesados en el español como lengua extranjera se centran en la metodología de la enseñanza-aprendizaje del español práctico (lo que, por supuesto, consideramos necesario y útil), pero son solo muy pocos los que prestan atención a los retos que supone enseñar los fundamentos de las principales disciplinas lingüísticas -sobre todo de la morfología y

\footnotetext{
1 Este trabajo fue presentado en el XIII Simposio Internacional de la SEDLL, celebrado en la Universidad de Belgrado (Serbia) del 20 al 22 de junio de 2019.
} 
la sintaxis- a estudiantes universitarios o de institutos bilingües en los países no hispanohablantes ${ }^{2}$. A pesar de ello, este último tema resulta muy interesante y didácticamente relevante por encerrar una circunstancia especial: nuestros alumnos son, por un lado, aprendices de ELE, es decir, aprenden la lengua en diferentes cursos prácticos, pero, por otro lado, son estudiantes de Filología Hispánica y, como tales, aprenden sobre la lengua en asignaturas obligatorias tales como Fonética y Fonología, Morfología, etc. Lógicamente, los dos aspectos que acabamos de mencionar -el práctico y el teórico- están interconectados también en el caso de la sintaxis. Al hacer análisis oracionales, nuestros alumnos cometen algunos errores, corregibles una vez detectados, que revelan su conocimiento deficiente del español práctico al igual que la existencia de ciertas interferencias entre los dos idiomas. Sin embargo, los mismos alumnos aprenden la sintaxis del español o, cuanto menos, las reglas básicas para el uso correcto del castellano como son la concordancia de tiempos, la rección verbal, etc. en las clases prácticas de la lengua española, sin saber siquiera que dichas reglas pertenecen al ámbito de la sintaxis. Hay que tomar en cuenta, además, que nuestros estudiantes de Grado tienen que familiarizarse con los fundamentos de la disciplina lingüística en cuestión y con el método del análisis oracional "a la española" en un solo semestre ${ }^{3}$. Como consecuencia, el docente puede no disponer de suficiente tiempo para profundizar en temas de incontestable interés teórico, experimentar o simplemente utilizar métodos interactivos; en otras palabras, debe limitarse, en no pocos casos, al método tradicional (exposición de la teoría + análisis sintácticos). Aun así, hay algunas cuestiones metodológicas particulares que merecen ser destacadas.

Por ejemplo, conviene preguntarse sobre la relevancia de los conocimientos previos de la sintaxis (del checo o el eslovaco, en nuestro caso) que poseen los alumnos. ¿Es un fundamento sólido sobre el que basar la exposición teórica de la sintaxis del español o se trata más bien de un impedimento u obstáculo? He aquí varios factores a considerar: a) en los estudiantes universitarios (con excepción de los de Bohemística), los conocimientos de la sintaxis del checo son ya bastante residuales o borrosos; b) los criterios definitorios y clasificatorios empleados en la lingüística española y la checa pueden ser -y son- diferentes; c) nuestros alumnos a lo mejor deberían conocer la concepción española de la sintaxis y no su interpretación checa o mixta, entre otras razones porque casi todos ellos pasarán al menos un semestre en alguna universidad española (y, por otra parte, hay estudiantes españoles de Filología Hispánica que se matriculan, dentro del programa Erasmust, en asignaturas impartidas en nuestro departamento). Por ello, creemos que es preferible separar claramente la sintaxis del español de la del checo. La aplicación de un enfoque contrastivo puede ser útil en algunos casos concretos -sobre todo para evitar errores de análisis debidos a la interferencia entre las dos lenguas -4 , pero en cuanto a la teoría sintáctica, la utilidad del método

\footnotetext{
2 En este contexto nos permitimos recomendar el nuevo libro del destacado morfólogo español David Serrano-Dolader Formación de palabras y enseñanza del español LE/L2. London / New York: Routledge, 2019.

${ }^{3}$ Los hispanohablantes, en cambio, empiezan a aprender esta técnica ya desde la escuela primaria.

4 Pongamos por caso el verbo ayudar, que lleva complemento directo en español (a pesar del leísmo frecuente) pero cuyo equivalente checo pomoci/pomáhat es un verbo con dativo. Otro ejemplo: en las oraciones impersonales con el verbo haber (p. ej. Hay tres problemas fundamentales...), un error
} 
contrastivo es relativamente limitada, lo que no quiere decir insignificante. A modo de ejemplo, para los lingüistas checos, el sintagma está formado por una "pareja sintagmática" (skladební dvojice) o sea, por dos elementos oracionales que guardan una relación sintáctica entre sí (sujeto - predicado; núcleo del predicado complemento directo; nombre - complemento del nombre, etc.). Esta concepción es fundamentalmente distinta de la española, según la cual se entiende por sintagma un elemento oracional -incluso una sola palabra- con función sintáctica. Así, la oración simple Juan estudia está constituida, de acuerdo con los lingüistas españoles, por dos sintagmas ( $S N=$ Juan, SV = estudia), mientras que su equivalente Jan studuje se analizaría, en la sintaxis checa, como un solo sintagma (S - P). Otra diferencia importante: para los alumnos checos resulta muy extraño aprender que las oraciones complejas no contienen ninguna oración principal pero sí una subordinada 5 , pues según los gramáticos checos, cada oración compuesta -con excepción de los períodos coordinados- consta de una oración principal y una o más subordinadas. En estos casos y otros similares, la contrastación de las dos concepciones (la española y la checa) es imprescindible; por otra parte, no estamos convencidos de que sea necesario o útil aplicar el método contrastivo a todos los conceptos y clasificaciones de la sintaxis, sobre todo si el objetivo principal es que el alumno aprenda los fundamentos de la disciplina según el modelo español.

\section{Selección de materiales didácticos}

Un verdadero reto para los profesores universitarios que imparten clases de sintaxis fuera de España o América Latina es la selección de materiales didácticos adecuados. A primera vista, se podría pensar que la mejor introducción a la sintaxis del español sería un manual escrito por un hispanista checo, eslovaco, polaco, serbio, etc., es decir, un lingüista con conocimientos sólidos de la concepción española y, a la vez, consciente de las particularidades de la enseñanza de dicha asignatura en un país no hispanohablante. En la República Checa se han publicado, hasta la fecha, al menos dos manuales que cumplen con las características mencionadas: Sintaxis del español actual (Zavadil y Čermák, 2019) y Sintaxis de la lengua española (Spitzová, 2000). Sin embargo, si el docente pretende exponer la materia siguiendo la tradición española (y señalar las diferencias con la sintaxis checa solo en casos necesarios, en vez de adoptar una perspectiva interpretativa), probablemente encontrará necesario acudir también a manuales de sintaxis publicados en España, aunque tampoco esta alternativa está exenta de dificultades. El mayor problema es la ausencia de una concepción unificada o

\footnotetext{
muy frecuente es interpretar el complemento directo como sujeto, precisamente por influencia del checo.

5 En su influyente Gramática didáctica del español, Gómez Torrego (2002: 260) afirma que "en una oración compleja no hay oración principal, pues la oración en ella integrada se subordina siempre a un elemento de la oración y no a otra oración". Como se explica en la Nueva gramática de la lengua española (NGLE, 2009: 3224), "las oraciones subordinadas sustantivas aparecen incrustadas en una unidad más amplia: Ia ORACIÓN PRINCIPAL. En el ejemplo propuesto, la oración principal es todo el texto que se reproduce: Los argentinos deseaban que se mantuviera la convertibilidad. A diferencia de lo que sostenían algunos gramáticos en la tradición, la oración principal no es los argentinos deseaban, es decir, lo que queda de la secuencia completa al retirar de ella la subordinada".
} 
estandarizada de la sintaxis del españole, lo que conduce a un caos terminológico y diferencias clasificatorias considerables.

Un excelente material didáctico que podemos recomendar sin reservas es el libro de Ginés Lozano Jaén Cómo enseñar y aprender sintaxis (2012), único y muy práctico por la acertada gradación de la dificultad de los contenidos (nivel básico, nivel intermedio y nivel avanzado). Mientras que la exposición destinada a los principiantes corresponde más o menos a la concepción tradicional, en los subcapítulos de nivel avanzado se presentan y comentan diferentes propuestas alternativas, entre ellas algunas contenidas en la Gramática didáctica del español de Leonardo Gómez Torrego7.

A pesar de no tratarse, evidentemente, de un manual de sintaxis en el sentido estricto, también la gramática de Gómez Torrego merece toda nuestra atención: primero, porque varias posturas teóricas no tradicionales del autor son aceptadas y respetadas por no pocos lingüistas españoles; y segundo, porque esta obra es utilizada para enseñar los fundamentos de la sintaxis del español en algunas universidades checas. Lejos de cuestionar su utilidad didáctica -incluso como material de referencia- en un curso avanzado (para contrastar la tradición sintáctica española con la concepción en muchos aspectos novedosa y teóricamente válida de Gómez Torrego), creemos que el uso de esta gramática como introducción a la sintaxis, o sea, en el nivel inicial, es más bien problemático, según trataremos de mostrar en el apartado 2. Por supuesto, además de los títulos anteriormente mencionados hay muchos otros manuales disponibles ${ }^{8}$, todos ellos con sus ventajas, desventajas y particularidades, así que lo ideal sería combinar varios materiales en función de la claridad de la explicación y la practicidad de los ejemplos empleados. Sin embargo, dada la pluralidad terminológica, conceptual y clasificatoria existente, es importante evitar la posible confusión de los alumnos, es decir, hay que tener cuidado con el uso selectivo de textos o ejemplos tomados de más de un manual. En el apartado siguiente nos ocuparemos de los casos más ilustrativos.

\section{Ejemplos de discrepancias teóricas en el ámbito de la sintaxis}

El primer caso que queremos comentar concierne a la función sintáctica del adjetivo que acompaña a un sustantivo. ¿̇Se trata de un elemento oracional con función de complemento del nombre (CN) o bien estamos ante un mero modificador/adyacente sin función sintáctica propia, comparable al determinante? Para los estudiantes de español checos, esta cuestión resulta casi inconcebible porque el llamado "modificador concordado" (př́vlastek shodný) es uno de los elementos oracionales más fácilmente reconocibles. Ahora bien, como apunta Gómez Torrego (2002: 290),

\footnotetext{
6 Nos referimos aquí al sistema educativo español y a los materiales didácticos disponibles, no al debate científico en sí (donde, por supuesto, la pluralidad de opiniones es absolutamente deseable y necesaria).

7 Esta gramática fue publicada originalmente en 1997 y cuenta con numerosas reediciones y varias revisiones. En el presente artículo citamos de la $8 .^{a}$ edición de 2002, prácticamente idéntica a la consultada por Lozano Jaén (9. ${ }^{\circ}$ ed. de 2007).

8 Entre otras publicaciones sobre el tema, véanse, p. ej., el Manual de sintaxis del español de Teresa María Rodríguez Ramalle (2005) o la Descripción gramatical del español. Didáctica del análisis sintáctico de Salvador y Antonio López Quero (2001).
} 
aunque todos los modificadores del sustantivo son en realidad complementos o adyacentes suyos, se suele reservar la denominación de complementos del nombre a aquellos modificadores que lo complementan mediante una preposición.

Consultando algunos manuales de sintaxis publicados en España, se puede comprobar que la realidad es incluso más compleja. Por ejemplo, Lozano Jaén (2012: 34) afirma que "los adyacentes o modificadores de un sintagma propician la interpretación semántica del mismo. Así, en el SN, un adjetivo o un S. Preposicional pueden funcionar como tales: Los chicos altos / Casa de piedra". A pesar de ello, de los ejercicios de análisis oracional incluidos en el libro se desprende que el autor citado analiza como $\mathrm{CN}$ únicamente los modificadores preposicionales?. Los hermanos López Quero (2001: 8), al igual que Benito Mozas (2004: 75), restringen de manera explícita la función de $\mathrm{CN}$ a los sintagmas preposicionales, en tanto que Cascón Martín (2000: 24) considera los dos tipos de adyacentes -los adjetivos y los preposicionales- modificadores semánticos, "puesto que, a diferencia de los determinantes, tienen valor conceptual propio. Tradicionalmente se les ha llamado complementos del nombre (CN)" 10 .

Esta falta de acuerdo entre los lingüistas españoles encierra un problema teórico y a la vez didáctico no desdeñable. La diferencia entre modificador adjetivo y modificador preposicional es sobre todo (si no puramente) formall ${ }^{11}$, así que desde el punto de vista funcional -y aquí estamos hablando de una función sintácticano existe ningún argumento de peso para sostener que el adjetivo adyacente no complementa al nombre al que acompaña. Por otra parte, el docente no puede simplemente pasar por alto $u$ ocultar esta discrepancia a sus alumnos, quienes inevitablemente se darán cuenta, al comparar ejemplos de análisis sintácticos de varios manuales, de que "algo no cuadra". Tomando en consideración las palabras de Gómez Torrego (2002: 290) de que "todos los modificadores del sustantivo son en realidad complementos o adyacentes suyos" y sumando a ello el hecho de que la tradición sintáctica checa coincide, en este caso, con la española (si hemos de creer a Cascón Martín, 2000: 24), la mejor solución parece ser analizar el adjetivo adyacente ${ }^{12}$ como CN. Al mismo tiempo, el profesor debe advertir a los estudiantes de las interpretaciones alternativas con las que puedan encontrarse. En todo caso, hay que evitar el relativismo, absolutamente indeseable en un curso de nivel inicial.

El segundo ejemplo ilustrativo es bien diferente del anterior. Tradicionalmente, la distinción entre atributo y complemento predicativo se fundamenta en la naturaleza del verbo con que se combinan (los verbos copulativos ser, estar y parecer ${ }^{13}$ frente a todos los demás). Una de las novedades de la Gramática

\footnotetext{
9 Por ejemplo, compárense los análisis de las oraciones 21 y 22 en Lozano Jaén (2012: 141).

10 En su capítulo de la Gramática descriptiva de la lengua española (GDLE), también Gemma Rigau (1999: 339) trata los adjetivos, al lado de los sintagmas preposicionales, como complementos del nombre.

11 Pongamos por caso los sintagmas nominales manifestación estudiantil y manifestación de estudiantes.

12 Por supuesto, con excepción de los determinantes o determinativos, entre los cuales se cuentan los adjetivos demostrativos, indefinidos, etc.

13 Sin embargo, mientras que "la mayor parte de los estudios gramaticales coinciden en determinar como copulativos propiamente dichos los verbos ser y estar", según constata Fernández Leborans en la
} 
didáctica de Gómez Torrego fue la sustitución de este criterio decisivo por otro, a saber, el de obligatoriedad (el atributo resulta imprescindible en la oración, mientras que el complemento predicativo es facultativo y, como tal, omisible; véase Gómez Torrego, 2002: 274). En la última gramática académica (NGLE, 2009: 2779) se introduce todavía otro criterio, también basado en la naturaleza del verbo (al igual que el criterio tradicional) pero, paradójicamente, con resultados casi idénticos a los que arroja el criterio de obligatoriedad de Gómez Torrego: el atributo en el sentido estricto se une con verbos copulativos y semicopulativos/pseudocopulativos (p. ej.: Me encuentro indispuesto; NGLE, 2009: 2778), en tanto que el complemento predicativo acompaña a verbos con significado pleno, o sea, a los verbos predicativos.

Todos los criterios arriba mencionados son claros, lógicos y deberían ser expuestos con detalle dentro de un curso avanzado, pero para los fines de la asignatura básica es suficiente atenerse al criterio tradicional (por supuesto, advirtiendo a los alumnos de la posibilidad de un análisis alternativo). Además, este problema teórico muestra bien la practicidad de la gradación didáctica del manual de Lozano Jaén, recomendado ya en el apartado anterior. En el subcapítulo 1.2.2. El predicado y sus clases (Lozano Jaén, 2012: 49-62), la diferencia entre oraciones atributivas y predicativas se explica primero, en el nivel inicial, exclusivamente a base del criterio tradicional (verbos copulativos vs. predicativos). En el apartado siguiente, de dificultad intermedia, ya se encuentra introducida la categoría de verbos semicopulativos o pseudocopulativos, cuyo complemento puede analizarse como atributo o predicativo ${ }^{14}$. Finalmente, en el nivel avanzado, en el que la exposición anterior viene ampliada con varias clasificaciones particulares, Lozano Jaén comenta las características (muy heterogéneas) de los tres verbos copulativos y cuestiona la claridad del criterio establecido en la NGLE (2009: 2835-2836) para diferenciar los verbos copulativos de los semicopulativos. Semejante gradación de dificultad se observa también en el subcapítulo dedicado al complemento predicativo (Lozano Jaén, 2012: 97-102)15.

El último caso especial merecedor de ser destacado concierne a la clasificación de las oraciones subordinadas (OS), divididas tradicionalmente en tres tipos: a) las sustantivas; b) las adjetivas o de relativo; y c) las adverbiales o circunstanciales. Quizás el mayor obstáculo para utilizar la Gramática didáctica de Gómez Torrego como material de referencia en las clases de nivel inicial es que, en la obra mencionada, el criterio categorial-funcional en que se basa la clasificación tradicional fue reemplazado por otro mucho más estricto: el de sustitución. Así, Gómez Torrego considera adverbiales tan solo aquellas oraciones que se pueden sustituir por un adverbio, lo que restringe significativamente el alcance del término oración adverbial (empleado en algunos manuales más tradicionales como

GDLE (1999: 2360), no hay tal unanimidad en cuanto al verbo parecer. Para más información sobre la difícil delimitación de los verbos copulativos con respecto a los pseudocopulativos, los semicopulativos y los predicativos, véase Fernández Leborans (1999: 2360-2364).

14 Véase el análisis de la oración El abuelo se encuentra enfermo en Lozano Jaén (2012: 53).

15 Sorprendentemente, Lozano Jaén no menciona allí, ni de paso, el relevante criterio de obligatoriedad de Gómez Torrego, a pesar de referirse a la Gramática didáctica del español en muchos otros pasajes de su manual. 
sinónimo de oración circunstancial) ${ }^{16}$. Este criterio es aplicado también a las subordinadas sustantivas, que deben ser sustituibles por un nombre o pronombre (con o sin preposición), pero ya no a las subordinadas adjetivas, definidas por Gómez Torrego (2002: 336) como "aquellas que desempeñan en la oración compleja el papel de un adjetivo [...], es decir, el de modificador de un sustantivo, pero sin preposición"17. Todo ello dificulta considerablemente el análisis sintáctico, y si los estudiantes checos, eslovacos, etc. aprendieran la práctica del análisis oracional siguiendo la concepción de Gómez Torrego, probablemente se quedarían perplejos ante la variedad de las subordinadas que tradicionalmente se clasificaban como adverbiales/circunstanciales sin más: OS sustantivas de complemento circunstancial, OS sustantivas de modificador del adverbio 18 , OS de relativo de modificador del adverbio ${ }^{19}$, OS realmente adverbiales, o sea, conmutables por un adverbio y, por fin, algunos tipos de oraciones circunstanciales que no son ni adverbiales ni sustantivas (por ejemplo, las condicionales y las concesivas).

En vista de este escollo, consideramos razonable utilizar preferentemente, en el nivel inicial, la clasificación tradicional de las subordinadas y dejar la exposición del criterio de sustitución establecido por Gómez Torrego y otros autores -con todas las complicaciones que conlleva- para una asignatura más avanzada, evitando así la desesperación o frustración de los principiantes.

Está claro que en los apartados anteriores no hemos agotado, ni mucho menos, todos los problemas metodológicos y teóricos relacionados con la enseñanza de la sintaxis del español como asignatura académica: a los casos ilustrativos arriba comentados podrían añadirse, entre otros, la existente pluralidad de los modelos de análisis sintáctico20, la diversidad de las clasificaciones de las oraciones coordinadas, etc., pero dado que un análisis pormenorizado de estos temas nos conduciría, en principio, a los mismos problemas didácticos que ya hemos expuesto anteriormente (y, además, el espacio limitado de este artículo no nos permite entrar

\footnotetext{
16 Según explica Lozano Jaén (2012: 268), "la gramática tradicional concebía las subordinadas adverbiales como segmentos que funcionaban igual que los complementos circunstanciales y las dividía en propias (lugar, tiempo y modo), las cuales podían ser conmutadas por un adverbio, e impropias (finales, causales, concesivas, condicionales, comparativas y consecutivas), cuyas oraciones carecen de la posibilidad de ser sustituidas por un adverbio". Vemos, pues, que el criterio de sustitución de Gómez Torrego no resulta, en principio, tan novedoso como pudiera parecer. Lo verdaderamente nuevo es la separación estricta de las oraciones adverbiales de las circunstanciales, que va mucho más allá de una simple división de las subordinadas adverbiales en propias e impropias (véase más adelante). Otras clasificaciones y/o terminologías alternativas pueden encontrarse p. ej. en López Quero y López Quero (2001) o en Benito Mozas (2004).

17 Conviene añadir que, en la concepción de Gómez Torrego, los términos oración adjetiva y oración de relativo no son sinónimos: para que una oración sea adjetiva y relativa a la vez, debe funcionar como modificador de un sustantivo y, además, debe ser introducida por un elemento relativo. Eso lleva al gramático español (Gómez Torrego, 2002: 340-341) a diferenciar entre las "oraciones de relativo no adjetivas" y las "oraciones adjetivas, pero no de relativo". Lozano Jaén (2012: 230-249) se ocupa de esta distinción en el subcapítulo 2.2.4.2. Nivel avanzado, pero utiliza los términos oración adjetiva y oración de relativo como sinónimos en el nivel intermedio (subcap. 2.2.4.1.), lo que consideramos adecuado.

18 P. ej.: Salimos después de que habíamos comido (Gómez Torrego, 2002: 335).

19 P. ej.: Ahora que no hay nadie, puedes hablarme (Gómez Torrego, 2002: 340).

20 Para un repaso de los diferentes modelos de análisis, véase Lozano Jaén (2012: 367-395).
} 
de pleno en la discusión teórica al respecto), podemos pasar ya a las conclusiones finales, que sintetizamos a continuación.

\section{Conclusiones}

Dada la ausencia de una concepción estandarizada de la sintaxis del español, la selección de materiales didácticos idóneos es una tarea absolutamente crucial y, a la vez, bastante difícil, sobre todo si el profesor pretende transmitir a sus alumnos los fundamentos de la sintaxis dentro del marco teórico y conceptual español. Según nuestra opinión y experiencia, la mejor opción es el manual de Lozano Jaén Cómo enseñar y aprender sintaxis (2012), muy práctico para ser utilizado tanto en clases de nivel básico como en un curso más avanzado (debido a la gradación de la dificultad de los contenidos).

Como los estudiantes de Filología Hispánica en las universidades checas, eslovacas, polacas, serbias, etc. aprenden la teoría y la práctica del análisis sintáctico desde cero, no consideramos didácticamente útil ni conveniente cargarlos con problemas teóricos más de lo necesario. El docente debería decidirse por una concepción o clasificación concreta, idealmente la más representativa o la menos complicada (lo cual, en la mayoría de los casos, supone atenerse a la tradición lingüística española), y eludir el relativismo en el nivel básico ${ }^{21}$.

Por otro lado, un análisis minucioso de las diferencias o discrepancias terminológicas, definitorias y de clasificación en el ámbito de la sintaxis puede ser sumamente útil para desarrollar el pensamiento lógico de aquellos estudiantes que ya tienen conocimientos sólidos de la materia ${ }^{22}$, o sea, para entrenar su capacidad de identificar los criterios clave subyacentes a determinadas propuestas innovadoras. Desde este punto de vista, la Gramática didáctica de Gómez Torrego (idealmente en combinación con el mencionado manual de Lozano Jaén y la NGLE, que también ofrece no pocas novedades de interés teórico) es un material inestimable.

Como nota final, cabe añadir que todas las recomendaciones contenidas en este artículo son meras sugerencias basadas en nuestra experiencia docente y no pretenden ser una fórmula universal para resolver los problemas arriba señalados: su utilidad dependerá tanto de los objetivos didácticos de la asignatura en cuestión como de las preferencias o prioridades de cada profesor.

\section{Bibliografía}

Benito MOZAS, A. (2004). Ejercicios de sintaxis. Teoría y práctica. Madrid: EDAF.

Cascón MARTín, E. (2000). Sintaxis. Teoría y práctica del análisis oracional. Madrid: Edinumen.

FERNÁNDEZ LeBORANS, M. J. (1999). La predicación: Las oraciones copulativas. In BOSQUE, I. \& DEMONTE, V. (dir.). Gramática descriptiva de la lengua española. Madrid: Espasa Calpe, vol. 2, pp. 2357-2460.

\footnotetext{
21 También a este respecto, el libro de Lozano Jaén resulta una herramienta muy práctica: en el nivel inicial se presentan conceptos, definiciones y clasificaciones tradicionales; en los niveles intermedio y avanzado, algunas concepciones alternativas.

22 Por ejemplo, dentro de una asignatura obligatoria u optativa de Máster (de nivel avanzado).
} 
GÓmez TORREGO, L. (2002). Gramática didáctica del español. Madrid: SM.

LÓPEZ QueRO, S. \& LÓPEZ QUeRO, A. (2001). Descripción gramatical del español. Didáctica del análisis sintáctico. Granada: Port-Royal.

LOZANO JaÉN, G. (2012). Cómo enseñar y aprender sintaxis. Modelos, teorías y prácticas según el grado de dificultad. Madrid: Cátedra.

Real Academia Española \& Asociación de Academias de la lengua Española (2009). Nueva gramática de la lengua española. Madrid: Espasa Libros.

RIGAU, G. (1999). La estructura del sintagma nominal: Los modificadores del nombre. In BOSQUE, I. \& DEMONTE, V. (dir.). Gramática descriptiva de la lengua española. Madrid: Espasa Calpe, vol. 1, pp. 311-362.

Rodríguez Ramalle, T. M. (2005). Manual de sintaxis del español. Madrid: Castalia.

SPItzovÁ, E. (2000). Sintaxis de la lengua española. Brno: Masarykova univerzita.

ZAVADIL, B. \& ČERMÁK, P. (2019). Sintaxis del español actual. Praha: Karolinum. 